\title{
Editorial
}

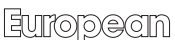

Addiction Research

\section{The European Innovation Express: Wim van den Brink Retires as Editor in Chief of European Addiction Research and Will Be Succeeded by Anna E. Goudriaan}
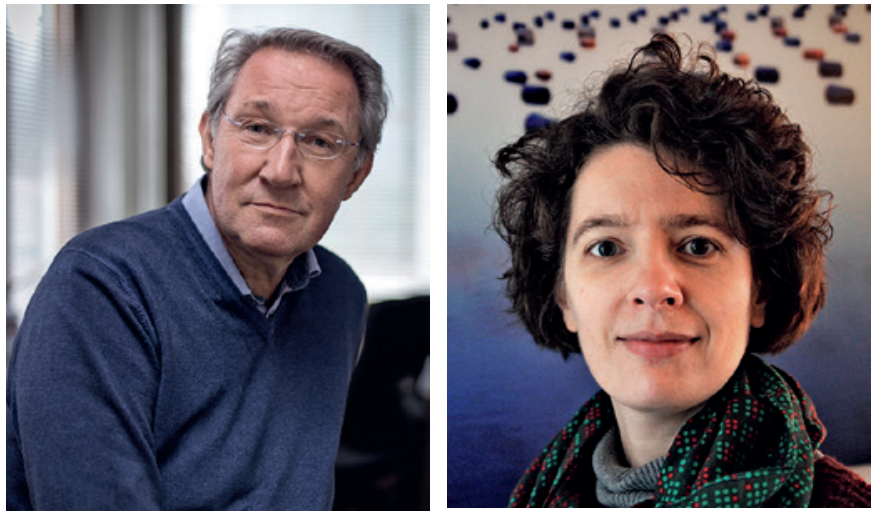

Wim van den Brink

Anna E. Goudriaan

Difficult to imagine nowadays but Amsterdam used to be a "trouble spot" in Europe in the 1990s as much as Frankfurt and Zurich with open drug scenes in the heart of Europe, lots of overdoses, and increasing incidence rates of HIV. The local tourist industry complained because of drug-related crime and it was a challenge for the health care system as well as Dutch drug policy. At that time, the approach in the Netherlands in dealing with substance use was already more open and less stigmatizing and the "coffee shops" were perceived as flood gates to the drug scene especially by the German government at that time. But the existing system was obviously unable to cope with the opiate challenge. It was one of these moments in Europe when a paradigm shift was needed to manage a growing public health crisis. For that you need people, who rise up to the challenge not only in their own country but in a true European spirit.

Wim van den Brink was certainly one the most influential of them, as a change agent on different levels. His involvement in the scientific work on heroin-assisted treatment was certainly of outstanding importance for the Netherlands and beyond. It was both clinically relevant and politically meaningful. Today, we know that it contributed to the regulation of this treatment in many countries and made it the intervention with the highest level of scientific evidence. At that time, it took a lot of energy to convince the research community and politicians to make it possible. A long journey for everybody involved but the best example possible of how research can contribute to solutions in troubled communities and even more for troubled individuals.

Amsterdam became a clinical and academic hub and a reference center at that time. The Jellinek Center as a clinical institution for addiction treatment as well as the Amsterdam Institute for Addiction Research at the Academic Medical Center of the University of Amsterdam set standards and became institutions that reflected the change. Much of that is owed to Wim van den Brink's 
pioneering work and dedication to both innovative research on the neurobiology of substance use disorders, and new pharmacological interventions and clinical trials in dual disorder patients, such as combined treatment trials for alcohol dependence and anxiety disorders, addiction and personality disorders, and addiction and attention deficit hyperactivity disorder (ADHD). Therefore, it is no surprise that he became one of the founders and he is still the president of the International Collaboration on ADHD and Substance Abuse (ICASA).

It is kind of typical that the scope of research of the Amsterdam Institute for Addiction Research (AIAR) was responding to changing needs and always tried to provide the necessary evidence to improve the system of care in a mix of curiosity and responsibility. Wim was the chair of 3 workgroups that developed the Dutch treatment guidelines on alcohol use disorders, opiate addiction, and nonopioid drugs. From "Rapid detox" to deep brain stimulation against substance use and trauma treatment to heroin-assisted treatment, only interventions that passed the test were approved and recommended. "Not driven by ideology" is probably the most appropriate description and contributed to an excellent treatment system with a high level of integration between substance use and mental challenges.

Being president of the scientific program of the European College of Neuropsychopharmacology (ECNP), Wim van den Brink stimulated the next generation of researchers to discuss their findings at European College of Neuropsychopharmacology meetings. Also as initiator and board member of the European Association of Substance Abuse Research (EASAR), he promoted young addiction researchers to present their work. As a mentor of over 70 $\mathrm{PhD}$ students, his work was taken over by multiple professorships in addiction in the Netherlands, ranging from addiction professorships in child psychiatry to neuroradiology and clinical psychology. This way, he has left a legacy of research groups and innovative addiction research for the future. It has inspired colleagues around Europe and contributed to the establishment of a European network of conferences and collaborations and in the founding of European Addiction Research (EAR) as a leading European Journal, which Wim pushed forward and shaped to a large degree for more than 10 years between 2008 and 2018.

Wim retired in 2018 from his position at the University of Amsterdam and started a new phase in his life. His energy, creativity, and dedication are special and will now be focused on new horizons. He will be an inspiration for the next generation of experts he helped to mentor so brilliantly. He is leaving a significant gap for EAR, because someone like him is not easily replaced. However, EAR attracted Anna E. Goudriaan as the new Co-Editor in Chief to follow in Wims footprints. Dr. Goudriaan is a neuropsychologist and licensed mental health psychologist, with a professorship focusing on the neurobiological mechanisms of substance use disorders and behavioral addictions and treatment innovation. She started her $\mathrm{PhD}$ on neurocognitive and neuroimaging studies in disordered gambling, which contributed to gambling being reclassified as the first behavioral addiction in Diagnostic and Statistical Manual of Mental Disorders, Fifth Edition. Currently, her main interests are to improve the understanding and treatment of addictive disorders through innovative neuromodulation and neurobiological research, personalized (e-health) interventions and treatment studies on comorbid addiction, and psychiatric disorders. As a new co-editor of EAR, she will enhance both interdisciplinary research and stimulate the publication of the rich scope of biological, psychological, and social studies of EAR and thus keep up the high standards for EAR as the leading European journal for substance use research.

Michael R. Krausz, Funding Editor Falk Kiefer, Editor in Chief 